\title{
Development of a conceptual framework for understanding financial barriers to care among patients with cardiovascular- related chronic disease: a protocol for a qualitative (grounded theory) study
}

\author{
David J.T. Campbell MD MSc, Braden J. Manns MD MSc, Brenda R. Hemmelgarn MD PhD, \\ Claudia Sanmartin PhD, Kathryn M. King-Shier RN PhD
}

\section{Abstract}

Background: Patients with cardiovascular-related chronic diseases may face financial barriers to accessing health care, even in Canada, where universal health care insurance is in place. No current theory or framework is adequate for understanding the impact of financial barriers to care on these patients or how they experience financial barriers. The overall objective of this study is to develop a framework for understanding the role of financial barriers to care in the lives of patients with cardiovascular-related chronic diseases and the impact of such barriers on their health.

Methods: We will perform an inductive qualitative grounded theory study to develop a framework to understand the effect of financial barriers to care on patients with cardiovascular-related chronic diseases. We will use semistructured interviews (face-to-face and telephone) with a purposive sample of adult patients from Alberta with at least 1 of hypertension, diabetes, heart disease or stroke. We will analyze interview transcripts in triplicate using grounded theory coding techniques, including open, focused and axial coding, following the principle of constant comparison. Interviews and analysis will be done iteratively to theoretical saturation. Member checking will be used to enhance rigour.

Interpretation: A comprehensive framework for understanding financial barriers to accessing health care is instrumental for both researchers and clinicians who care for patients with chronic diseases. Such a framework would enable a better understanding of patient behaviour and nonadherence to recommended medical therapies and lifestyle modifications.

ardiovascular-related chronic diseases such as hypertension, diabetes, stroke and coronary artery disease are among the leading causes of morbidity and mortality in Canada. ${ }^{1,2}$ Hospital services and medically necessary physician services are covered by Canada's universal public health insurance. ${ }^{3}$ Despite the increasingly important role of medications and services of allied health care providers in managing outpatients with chronic diseases, ${ }^{4}$ these are not universally included within Canadian health care insurance. For example, public insurance plans for outpatient prescription medications vary by province, but no province offers universal public medication insurance without some cost. ${ }^{5}$ Those fortunate enough to qualify for public medication insurance are still faced with considerable copayments or deductibles or both. ${ }^{6}$ Thus, financial constraints can have a significant impact on the care required to optimize outcomes in people with cardiovascular-related chronic diseases. ${ }^{7}$ In fact, many patients face barriers to obtaining adequate health care, such as necessary prescription medications, owing to the costs associated with these services. ${ }^{8}$

There are several types of financial barriers that may reduce accessibility to necessary care and impact health outcomes. Some people may not be able to afford the direct costs associated with medications, self-monitoring supplies, rehabilitation or home care (such as insurance premiums and user charges). Others may struggle to access care that is fully funded by the public system because of an inability to afford the indirect costs associated with appointments (e.g., lost

Competing interests: None declared.

This article has been peer reviewed.

Correspondence to: David Campbell, dcampbel@ucalgary.ca CMAJ Open 2016. DOI:10.9778/cmajo.20160030 
income from taking time off work, transportation, parking, child care). A previous survey conducted by our group showed that $12 \%-20 \%$ of Canadians with cardiovascular-related chronic diseases experienced financial barriers, and emergency department visits or hospital admissions were $70 \%$ more likely among these people than among those who did not experience financial barriers. ${ }^{9}$ These adverse outcomes may be potentially avoidable if financial barriers could be addressed. It is therefore important to understand how patients come to perceive a financial barrier, the role of financial barriers in their lives and the impact of such barriers on their health.

Researchers often use theories or frameworks to understand how social phenomena are operationalized. In preparing to design a survey focused on financial barriers, we were unable to identify a theory or framework that adequately described how financial barriers are experienced or how they affect health care and outcomes. Rather, we found a number of frameworks that touch on relevant aspects of care seeking. There are 3 types of frameworks that relate to understanding financial barriers to health care: frameworks dealing with access to care in a general sense, health economics frameworks for understanding health-related decision-making and behaviour, and frameworks focusing on the impact of social determinants of health or socioeconomic status on health resource use.

Several authors have attempted to create frameworks to comprehensively understand access to care for patients with chronic diseases. ${ }^{10-13}$ Finances are often considered as an aspect of access to care in these frameworks, but the focus of attention is not on how patients experience financial barriers. The breadth of these frameworks is often viewed as a strength as they are able to consider a variety of potential barriers at many different levels. However, taking such a broad perspective on the overarching topic of access also limits the degree to which they can attempt to fully comprehend a construct such as financial barriers.

Grossman's ${ }^{14}$ health production model is an economic approach to understanding people's decision-making around health. There are limitations to and criticisms of Grossman's theory, primarily related to the economic practice of simplifying the complexities of the human condition to a point where theories can be tested empirically. ${ }^{15}$

A number of frameworks, including that proposed by Brown and colleagues, ${ }^{16}$ focus on the impact of social determinants of health or socioeconomic status on access to health care services. ${ }^{17,18}$ These frameworks are limited by their complexity and the significant interconnectedness of a multitude of individual and community factors, which make them difficult to apply in practice. Although both Grossman's model and Brown and colleagues' framework are helpful for understanding access to care, they both have significant limitations for understanding the role of financial barriers (Table 1). Furthermore, it is feasible that even people who may be consid-

Table 1: Strengths and limitations of Grossman's ${ }^{14}$ model of health production and Brown and colleagues ${ }^{16}$ framework of socioeconomic position in health

\begin{tabular}{|c|c|c|c|c|}
\hline \multirow[b]{2}{*}{ Variable } & \multicolumn{2}{|c|}{ Model of health production } & \multicolumn{2}{|c|}{ Framework of socioeconomic position in health } \\
\hline & Strengths & Limitations & Strengths & Limitations \\
\hline Generalizability & $\begin{array}{l}\text { Applicable to a variety } \\
\text { of conditions }\end{array}$ & $\begin{array}{l}\text { May be overly } \\
\text { simplified to apply in all } \\
\text { circumstances }\end{array}$ & $\begin{array}{l}\text { Thought to be applicable to } \\
\text { other chronic health } \\
\text { conditions }\end{array}$ & $\begin{array}{l}\text { Derived only from } \\
\text { participants with diabetes }\end{array}$ \\
\hline Endogeneity & $\begin{array}{l}\text { By separating the } \\
\text { investment and } \\
\text { consumption demand } \\
\text { for health, it is able to } \\
\text { account for endogeneity }\end{array}$ & - & - & $\begin{array}{l}\text { Unable to tease apart } \\
\text { reverse causation } \\
\text { between socioeconomic } \\
\text { position and health }\end{array}$ \\
\hline $\begin{array}{l}\text { Definition of } \\
\text { socioeconomic status/ } \\
\text { position }\end{array}$ & - & $\begin{array}{l}\text { Narrow: considers } \\
\text { income only }\end{array}$ & $\begin{array}{l}\text { Broad: considers a } \\
\text { multitude of factors }\end{array}$ & $\begin{array}{l}\text { Does not consider } \\
\text { psychosocial variables }\end{array}$ \\
\hline $\begin{array}{l}\text { Evidence/empiric } \\
\text { support }\end{array}$ & $\begin{array}{l}\text { Many studies support } \\
\text { model }\end{array}$ & $\begin{array}{l}\text { Some studies refute } \\
\text { certain aspects of } \\
\text { model }\end{array}$ & $\begin{array}{l}\text { One recent study validates } \\
\text { several components of } \\
\text { framework }\end{array}$ & $\begin{array}{l}\text { No other studies support } \\
\text { framework }\end{array}$ \\
\hline $\begin{array}{l}\text { Ability to use for } \\
\text { prediction }\end{array}$ & $\begin{array}{l}\text { Simplified model allows } \\
\text { one to assess how } \\
\text { changes in } 1 \text { variable } \\
\text { will affect demand for } \\
\text { health }\end{array}$ & $\begin{array}{l}\text { Overemphasizes } \\
\text { individuals' agency } \\
\text { without consideration of } \\
\text { their circumstances }\end{array}$ & - & $\begin{array}{l}\text { Model too complex to be } \\
\text { used to predict health- } \\
\text { care-seeking behaviours }\end{array}$ \\
\hline $\begin{array}{l}\text { Possible result of using } \\
\text { framework/model to } \\
\text { understand financial } \\
\text { barriers }\end{array}$ & - & $\begin{array}{l}\text { Victim blaming: does } \\
\text { not acknowledge the } \\
\text { social determinants of } \\
\text { one's willingness to pay } \\
\text { for services }\end{array}$ & - & $\begin{array}{l}\text { Fatalism: has such a } \\
\text { complex view of how } \\
\text { socioeconomic position } \\
\text { contributes to health care } \\
\text { access that it is difficult to } \\
\text { create interventions to } \\
\text { address these barriers }\end{array}$ \\
\hline
\end{tabular}


ered to be of higher socioeconomic status may encounter financial barriers to care under certain circumstances (e.g., lack of health insurance).

Given that none of the frameworks or models that we have found are ideal for understanding the impact of financial barriers to care on people with cardiovascular-related chronic disease or how patients experience financial barriers, a novel model or framework is required. Inductive qualitative research has as its goal the generation or development of a theory or framework. Our objective is to use an inductive qualitative method (grounded theory) to develop a framework for understanding the role of financial barriers to care in the health of patients with cardiovascular-related chronic health diseases. Specific objectives include: to explore and describe the circumstances that contribute to a person's experiencing financial barriers; to explore what factors affect how impactful a financial barrier may be for a given patient; to explore the coping strategies used by patients with chronic diseases to overcome financial barriers, and at what cost; and to understand what patients feel may improve their access to care and help overcome their financial barrier.

\section{Methods}

\section{Study design}

This study will be informed by our previous research on financial barriers to care. ${ }^{9}$ We conducted a survey of western Canadians with cardiovascular-related chronic diseases $(n=$ 1849) to understand the barriers that they faced in self-managing their conditions. We found that financial barriers were common $(12 \%-20 \%$ of patients) and that there were significant associations between financial barriers and clinically meaningful outcomes (medication nonadherence, emergency department visits and hospital admissions). In the absence of a framework for understanding how financial barriers are experienced by individual patients, we have been unable to conceptualize the mechanisms by which financial barriers may translate into adverse clinical outcomes.

The aim of pursuing qualitative research is to gain an indepth understanding of experiences and processes such as people's behaviours, motivations and perceptions. Qualitative methods are useful in studying topics that cannot be quantified, such as experiences and coping strategies. ${ }^{19} \mathrm{We}$ aim to thoroughly explore the experience of patients with cardiovascular-related chronic conditions who have financial barriers to care, and therefore our research question necessitates the use of qualitative methods to probe deeply into this personal process.

Grounded theory allows researchers to move beyond simple description to a more abstract theory or framework of a given human process. Grounded theory is used to describe processes of human behaviour ${ }^{20}$ through generation of frameworks and theories. ${ }^{21}$ The principle of constant comparison is used to ensure that the theory generated is in fact grounded in the data rather than in preconceived notions. We chose to use grounded theory methodology with the goal of moving beyond a superficial description of the experiences of patients with financial barriers to care to a more theoretical and analytic description of the process of experiencing and coping with such a barrier.

\section{Sampling and data collection}

\section{Inclusion criteria}

The study population will consist of English-speaking adults (age $>30 \mathrm{yr}$ ) in Alberta with at least 1 of the following selfreported chronic medical conditions: hypertension, diabetes, coronary artery disease and stroke. To be eligible, participants must identify as having experienced a financial barrier within the previous year by answering affirmatively to the following question (used to define the exposure in the preceding quantitative study ${ }^{9}$ :

Some people have difficulty paying for services, equipment, and medications for chronic conditions. Other people may have difficulty paying for transportation or childcare to allow attendance at doctors' appointments ... In the past 12 months did you have difficulty paying for services, equipment, medications for your chronic conditions?

\section{Exclusion criteria}

People who are unable to converse in English (owing to language barriers or physical impediments), those who do not have at least 1 of the specified chronic conditions of interest and those with severe cognitive impairment will be excluded from participation in the study.

\section{Recruitment}

We will recruit study participants via telephone self-referral in response to signage in family physicians' offices and specialist clinics as well as by telephoning people who have participated in previous research and who have consented to be contacted for future studies. We have planned a strategy of theoretical or purposeful sampling ${ }^{22}$ by identifying a number of strata that are important to be represented in our pool of participants, as these variables were notable contributors to the presence of financial barriers to care in our prior survey:

- Age: 65 years or more, and less than 65 years (as government-sponsored health benefits are provided to those aged 65 years or more)

- Sex

- Type of chronic disease

- Multimorbidity

- Aboriginal status

- Adequate and low health literacy $y^{23}$

\section{Data collection}

We will collect data using semistructured face-to-face or telephone interviews. We have developed an interview guide based on the findings of our previous survey ${ }^{9}$ and learnings from related frameworks (Appendix 1, available at www. cmajopen.ca/content/4/2/E304/suppl/DC1). The interviewer will record thoughts and insights in field notes during and 
after each interview. D.C. (a physician with graduate training in medical anthropology and several years of experience collecting qualitative data, and currently a $\mathrm{PhD}$ student) will be the principal interviewer. He will not have preexisting clinical relationships with the participants. Participants will be made aware that the interviewer is interested in obtaining their perspectives to give voice to their experiences with financial barriers.

Five domains will be explored in the interview: the patient's experience of living with chronic disease, experience of financial barriers, perceived reasons for financial barriers, health consequences of financial barriers and mechanisms for coping with financial barriers. Interviews will be digitally recorded and subsequently transcribed verbatim with the use of standard linguistic conventions by a professional transcriptionist.

\section{Sample size}

Data collection and analysis will occur simultaneously, which will allow us to continue sampling and data collection until theoretical saturation is achieved. Saturation will be deemed to have been met once 3 consecutive interviews do not yield any new substantive codes during initial analysis. Based on previous reports of grounded theory studies of this nature, ${ }^{24}$ we anticipate needing to complete 30-50 interviews to achieve saturation.

\section{Data analysis}

We will employ grounded theory coding with an inductive approach, ${ }^{25}$ using techniques described by Strauss and Corbin. ${ }^{26}$ Data collection and analysis will be done iteratively, which will allow us to "explore and fill out these codes" 25 as necessary. Data analysis will begin after each interview, when the interviewer will reflect on the theoretical content in the interview and write memos to record analytic ideas. We will analyze the finalized transcriptions using NVivo 10 software.

Initial, or open, coding will proceed in a line-by-line fashion. During this process, the data will be "fractured," or broken down into granular codes. ${ }^{20}$ Further analyses will be based on the principle of constant comparison. ${ }^{21}$ First, data from interview transcripts will be compared internally, after which transcripts will be compared with one another by means of incident-to-incident coding. The process of initial coding will be done individually in triplicate, meaning that 3 experienced analysts will individually code the data. All coders will meet weekly to discuss their interpretations of the data to allow for consideration of various perspectives. Given that this research is informed by the interpretive paradigm, exact agreement is not the goal of these sessions; rather, the aim is to gather a multitude of viewpoints on the various incidents and themes derived from the data. However, consensus about how to code a given piece of data will be achieved after thorough discussion of each point. In cases in which consensus is not reached, allowances will be made such that a passage may retain multiple codes to enable future discussion.

Once all transcripts have been initially coded, we will proceed with focused coding, during which we will group initial fractured codes into coherent subsuming categories. The final analytic stage will be axial coding: the research team will meet to discuss the relations between the various codes and categories while reviewing pertinent excerpts from the data.

\section{Rigour}

We will use several procedures to maximize the rigour and enhance the trustworthiness of this qualitative study. Member checking (the process of presenting research findings to participants to obtain their feedback) will be accomplished by holding 2 focus groups of participants who take part in the interview portion of the study. The use of multiple analysts will enrich our ability to interpret and understand incidents described by respondents. Negative case sampling (selecting participants who stated that they had experienced financial difficulties associated with their chronic condition but that they would not describe these as "barriers") will help illuminate why financial issues may be more or less pertinent for some patients than for others. Extreme case sampling will involve including patients who had a hospital admission or experienced an adverse event that was directly attributable to their financial barriers. Finally, throughout the process of data collection and analysis, we will actively use the principle of reflexivity: thinking about how our own personal experiences and characteristics may shape participants' responses or our interpretations. ${ }^{27}$

\section{Ethics approval}

Ethics approval has been obtained from our institution's Conjoint Health Research Ethics Board, and study procedures will be in accordance with Canada's Tri-Council Policy Statement guidelines. ${ }^{28}$ Informed consent will be received verbally over the telephone for interviews, and written consent will be obtained for focus group participation.

\section{Interpretation}

Although a substantial proportion of Canadians with chronic diseases experience financial barriers to accessing health care, there are currently no frameworks or theories that adequately represent the patient experience or can be used to guide interventions to minimize the impact of these barriers. We propose a rigorous qualitative (grounded theory) study using data derived from semistructured patient interviews to develop a novel framework to enhance our ability to understand the role of financial barriers in patients' lives and health outcomes.

\section{Limitations}

We acknowledge that the small sample in this qualitative study may not be fully representative of the Canadian population. As such, some groups (e.g., those who do not speak English and those with communication limitations) will not be represented in the sample. Thus, the study findings may not necessarily be transferable to these groups of patients. However, the use of a purposive sampling strategy will minimize the problems caused by nonrepresentativeness. 


\section{Conclusion}

We are optimistic that the development of a comprehensive framework to understand the experience of financial barriers to health care faced by patients with cardiovascular-related chronic diseases will be educational and highly relevant for policy-makers, clinicians and health services researchers. Through our framework, we hope to generate an understanding of how and why some patients come to experience financial barriers. This may be useful for informing future health policy around health care accessibility. Furthermore, the development of a framework to understand this particularly vexing problem would also be of value to individual clinicians who care for patients with chronic diseases and who may not fully understand the barriers that prevent their patients from being adherent to recommended medical and lifestyle therapies. Finally, we plan to use the findings from this study to help design and test interventions to minimize the impact of financial barriers to accessing care on patient-relevant outcomes.

\section{References}

1. Mortality, summary list of causes 2008. Ottawa: Statistics Canada; 2011

2. Tracking heart disease and stroke in Canada. Ottawa: Public Health Agency of Canada; 2009.

3. Marchildon G. Health systems in transition: Canada. Geneva: World Health Organization; 2013.

4. Bodenheimer T, Wagner EH, Grumbach K. Improving primary care for patients with chronic illness. FAMA 2002;288:1775-9.

5. Daw JR, Morgan SG. Stitching the gaps in the Canadian public drug coverage patchwork? A review of provincial pharmacare policy changes from 2000 to 2010. Health Policy 2012;104:19-26.

6. Demers V, Melo M, Jackevicius C, et al. Comparison of provincial prescription drug plans and the impact on patients' annual drug expenditures. CMAf 2008; $178: 405-9$.

7. Simpson J. Chronic condition: why Canada's bealth-care system needs to be dragged into the 21st century. Toronto: Allen Lane; 2012.

8. Schoen C, Doty MM. Inequities in access to medical care in five countries: findings from the 2001 Commonwealth Fund International Health Policy Survey. Health Policy 2004;67:309-22.

9. Campbell DJ, King-Shier K, Hemmelgarn BR, et al. Self-reported financial barriers to care among patients with cardiovascular-related chronic conditions. Health Rep 2014;25:3-12.

10. Aday LA, Andersen R. A framework for the study of access to medical care. Health Serv Res 1974;9:208-20.

11. Carillo JE, Carillo VA, Perez HR, et al. Defining and targeting health care access barriers. 7 Health Care Poor Underserved 2011;22:562-75.

12. Barr VJ, Robinson S, Marin-Link B, et al. The expanded Chronic Care Model: an integration of concepts and strategies from population health promotion and the Chronic Care Model. Hosp Q 2003;7:73-82.

13. Levesque JF, Harris MF, Russell G. Patient-centred access to healthcare: conceptualising access at the interface of health systems and populations. Int $\mathcal{f}$ Equity Health 2013;12:18.
14. Grossman M. On the concept of health capital and the demand for health. $\mathcal{F}$ Polit Econ 1972;80:223-55.

15. Laporte A. Should the Grossman model retain its iconic status in bealth economics? Toronto: Canadian Centre for Health Economics; 2014.

16. Brown AF, Ettner SL, Piette J, et al. Socioeconomic position and health among persons with diabetes mellitus: a conceptual framework and review of the literature. Epidemiol Rev 2004;26:63-77.

17. Adler NE, Ostrove JM. Socioeconomic status and health: what we know and what we don't. Annals N Y Acad Sci 1999;896:3-15.

18. Frieden TR. A framework for public health action: the health impact pyramid. Am 7 Public Health 2010;100:590-5.

19. Sandelowski M. Qualitative analysis: what is it and how to begin. Res Nurs Health 1995;18:371-5.

20. Green J, Thorogood N. Qualitative methods for health research. Thousand Oaks (CA): SAGE Publications; 2009.

21. Glaser B. The constant comparative method of qualitative analysis. Soc Probl 1965;12:436-45.

22. Sandelowski M. Sample size in qualitative research. Res Nurs Health 1995;18: 179-83.

23. Chew LD, Griffin JM, Partin MR, et al. Validation of screening questions for limited health literacy in a large VA outpatient population. 7 Gen Intern Med 2008;23:561-6.

24. Morse J. Designing funded qualitative research. In: Denzin N, Lincoln Y, editors. Handbook of qualitative research. Thousand Oaks (CA): SAGE Publications; 1994. p. 220-35.

25. Charmaz K. Constructing grounded theory. 2nd ed. Los Angeles: SAGE Publications; 2014.

26. Strauss A, Corbin J. Basics of qualitative research. Thousand Oaks (CA): SAGE Publications; 1998.

27. Cohen D, Crabtree B. Qualitative research guidelines project. Princeton (NJ): Robert Wood Johnson Foundation; 2006. Available: www.qualres.org/ HomeRefl-3703.html (accessed 2016 Jan. 20).

28. Canadian Institutes of Health Research, Natural Sciences and Engineering Research Council of Canada, Social Sciences and Humanities Research Council of Canada. Tri-Council policy statement: ethical conduct for research involving humans. Ottawa; 2014. Available: http://pre.ethics.gc.ca/pdf/eng/ tcps2-2014/TCPS_2_FINAL_Web.pdf (accessed 2016 June 3).

Affiliations: Department of Community Health Sciences (Campbell, Manns, Hemmelgarn, Sanmartin, King-Shier); Department of Medicine (Campbell, Manns, Hemmelgarn), Cumming School of Medicine, University of Calgary, Calgary, Alta.; Health Analysis Division (Sanmartin), Statistics Canada, Ottawa, Ont.; Faculty of Nursing (King-Shier), University of Calgary, Calgary, Alta.

Contributors: All of the authors contributed to the development, writing and revising of this research protocol, approved the final version to be published and agreed to act as guarantors of the work.

Funding: David Campbell is funded by an Alberta Innovates - Health Solutions Clinician Fellowship. This research will also be supported through the Alberta Innovates - Health Solutions Collaborative Research and Innovation Opportunities grant to the Interdisciplinary Chronic Disease Collaboration.

Supplemental information: For reviewer comments and the original submission of this manuscript, please see www.cmajopen.ca/content/4/2/ E304/suppl/DC1 